\title{
Optical Coherence Tomography: imaging of age related maculopathy
}

\author{
V Scorcia*, M Rechichi \\ From de Senectute: Age and Health Forum \\ Catanzaro, Italy. 5-7 December 2009
}

\section{Background}

Age-related macular degeneration (AMD) is the leading cause of severe vision loss in the developed world in patients over 60 years. AMD is characterized by two distinct forms: dry and wet. Optical coherence tomography (OCT) is a non-invasive, useful and reproducible diagnostic tool that provides cross-sectional images of retina and has a primary role for diagnostic and therapeutic management of AMD. The spread of antiVEGF intravitreal injection for therapy of wet AMD further emphasized the role of OCT for treatment algorithms allowing a precise characterization of lesions and strict non-invasive retinal monitoring in the follow-up.

Main indications and limits of OCT will be discussed as well as the various morphological presentations of dry and wet AMD underlying retinal changes before and after therapy.

\section{Materials and methods}

We analyzed 500 eyes of 270 patients affected by dry or wet AMD that underwent a complete ophthalmological examination and OCT scan with two different machines. A time domain OCT (TD-OCT, Stratus OCT3, Carl Zeiss Meditec, Dublin, CA) and a Fourier Domain OCT (FD-OCT, RTVue-100, Optovue, Fremont, CA).

We used a radial line pattern scan algorithm with TD-OCT (see Figure 1) and radial and raster scan with FD-OCT with additional tridimensional reconstruction (see Figure 2).

\section{Results}

B-scan analysis of two instruments allows detailed reproduction of anatomical retinal layers in AMD. FD-OCT images are more accurate and the computing process allows tridimesional reconstruction of sagittal and coronal plane.

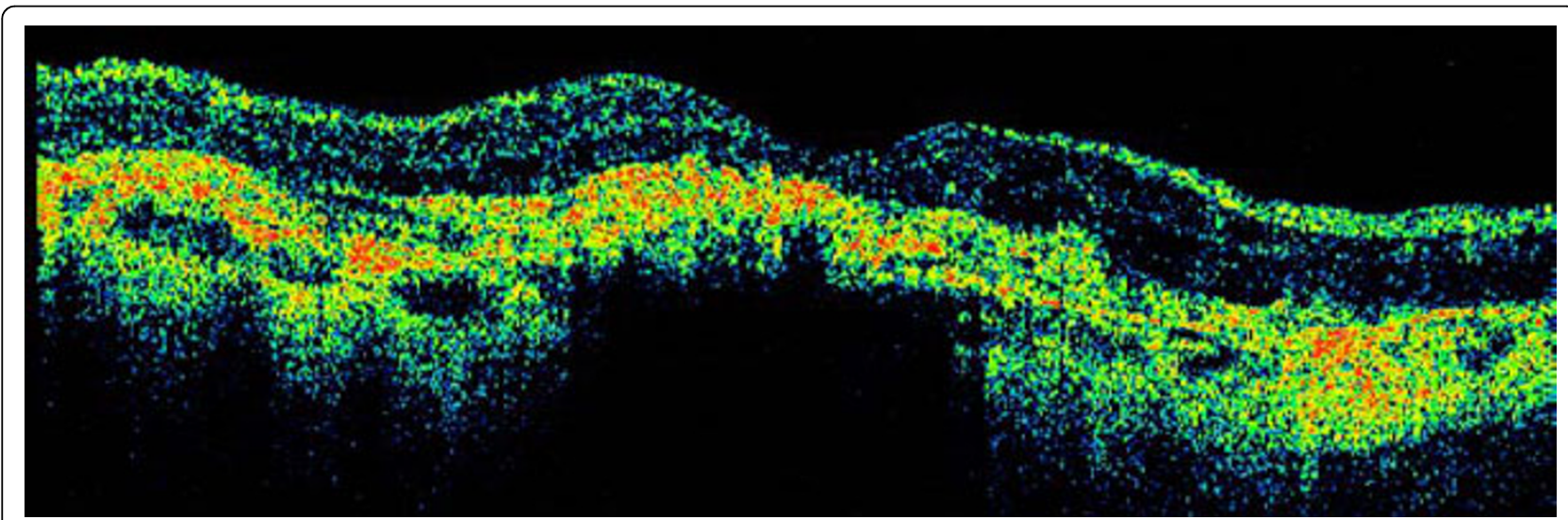

Figure 1 B-Scan image of TD-OCT with wet AMD 


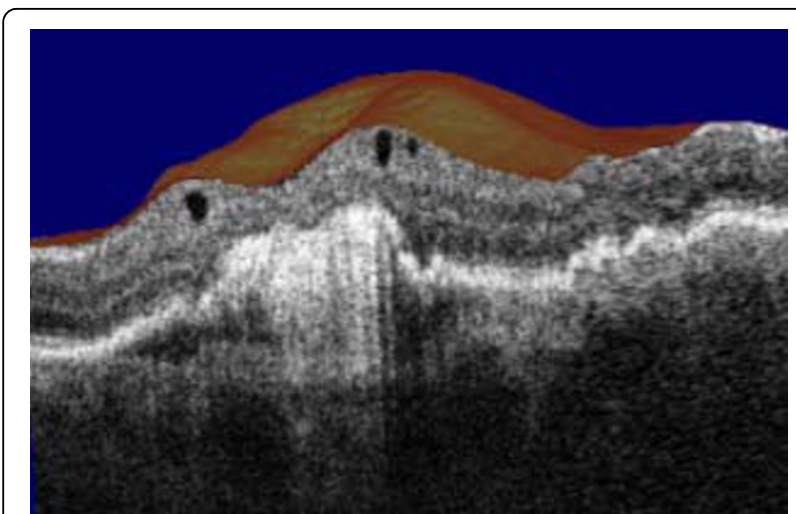

Figure 2 Tridimentional reconstruction of wet AMD (FourierDomain $\mathrm{OCT}$ ).

\section{Conclusions}

Optical coherence tomography is a simply, non-invasive and reproducible technique for retinal imaging in patients with AMD. The spread of FD-OCT allows a precise characterization of AMD and accurate analysis of intraretinal layers. Tridimentional reconstruction tomography improves the visualization of photoreceptor morphology.

Published: 19 May 2010

doi:10.1186/1471-2318-10-S1-A78

Cite this article as: Scorcia and Rechichi: Optical Coherence

Tomography: imaging of age related maculopathy. BMC Geriatrics 2010 10(Suppl 1):A78.
Submit your next manuscript to BioMed Central and take full advantage of:

- Convenient online submission

- Thorough peer review

- No space constraints or color figure charges

- Immediate publication on acceptance

- Inclusion in PubMed, CAS, Scopus and Google Scholar

- Research which is freely available for redistribution

Submit your manuscript at www.biomedcentral.com/submit
Biomed Central 